\title{
AS PRIMEIRAS RELAÇÕES ENTRE A FRANÇA E O BRASIL: DOS VERRAZANI A VILLEGAINON $(*)$.
}

\author{
MICHEL MOLLAT \\ Professor da Sorbonne (Paris).
}

A comemoração das viagens de Giovanni da Verrazano (1) nos pareceu oportuna para voltarmos a falar sôbre o papel desempenhado por êsse explorador e pelo seu irmão Girolamo na participação francesa nos Grandes Descobrimentos Marítimos. Aproveitamos a ocasião para precisar o que já escrevemos sôbre êsse assunto (2), com o auxílio de novos documentos e pela oportunidade que tivemos de uma visita a certos lugares freqüientados no Brasil por êsses viajantes do século XVI.

A documentação que utilizamos provém essencialmente de fontes francesas e portuguêsas. Os Arquivos do Departamento de SeineMaritime conservam os atos lavrados perante tabelião e as sentenças do Parlamento de Ruão; a Tôrre do Tombo, em Lisboa, contém igualmente peças do processo, mas sobretudo uma correspondência diplomática de grande precisão; a Biblioteca Nacional de Paris possui uma curiosa coleção de documentos que pertenceram, segundo nos parece, a um armador normando, sem esquecer as fontes do Fundo das Cartas e Planos. A essa informação primordial devemos acrescentar algumas peças dos Arquivos de Calvados, dos Arquivos Nacionais de Paris e do Public Record Office. Uma parte sòmente

(*). - Texto de conferência pronunclada em Paris, na Academia da Marinha, em 9 de março de 1962. Publicada nos Cahiers de l'Institut des Hautes Etudes de l'Amérique Latine n.: 6. Tradução de Eurípedes Simōes de Paula.

(1). - Em Florença em particular, em 21 e 22 de outubro de 1961 . Um conjunto de trabalhos sôbre o assunto deverá ser publicado sob a direçấo do Prof. F. Melis.

(2). - Tomamos a liberdade de encaminhar o leltor para os nossos próprios trabalhos sôbre o assunto: Un voyage du Girolamo Verrazano au Brésit en 1529 (in "Cahier des Annales" no 4, A travers les Amériques latines, 1949, pp. 184-189); Quelques aspects de la vie économique et sociale de la France de la première moitié au XVle siecle vus à travers la correspondance des aiplomates portugais (in "Bull. Et. Portug.", 1949); Le commerce maritime normand à la fin du Moyen-Âge (Paris, 1952).

A situação atual da questão fol apresentada em 1960, no tomo I (A Epoca Colonial) da História Geral da Civiliagcão Brasileira sob a direção de Sérgio Buarque de Holanda (Sáo Paulo, 1960). Isso nos dispensará de anotar, mais uma vez, as obras anteriores, de Varnhagen a Baiāo. 
da documentação concernente aos irmãos Verrazani já foi impressa; certos documentos parecem ter sido até hoje completamente desconhecidos.

O primeiro episódio conhecido do encôntro da França e do Brasil é muito célebre para nêle nos determos. Da viagem concebida por Paulmier de Gonneville

$$
\text { "en trafiquant en Lissebonne", }
$$

sabe-se, pela sua relação (3), que ela se desenrolou de 24 de junho de 1503 a 7 de maio de 1505 , data em que o Espoir foi capturado pelos corsários inglêses, ao largo da ilha de Jersey. Tendo transposto o Equador em 12 de setembro, atingiu a costa do Brasil meridional em 5 de janeiro de 1504 e talvez tenha tocado no estuário do Rio São Francisco do Sul; remontou em seguida do Sul para o Norte, aportando provàvelmente na costa perto de Pôrto Seguro e Salvador. Além dessa indicação incerta, ainda que verossímel, dêsses pontos de desembarque, sòmente levaremos em conta, de um conjunto de fatos conhecidos, a natureza dos objetivos e os resultados imediatos da viagem: à "curiosidade" da exploração, no dizer do próprio Gonneville, se juntava a intenção mercantil; $\cdot o$ carregamento de volta compunha-se de

$$
\text { "peles, plumagens e raizes para tingir" (4), }
$$

isto é, o famoso pau-brasil de que nos ocuparemos mais adiante, adquirido dos índios carijós e tupinambás mediante trocas pacíficas; enfim, estava presente a bordo o jovem índio Essomériq, o qual fôra feito cristão e era seu sobrinho por aliança matrimonial (5).

Além dêsses esclarecimentos, as próprias semelhanças não são certezas. Teríamos tido prazer em confirmar a modéstia do propósito com que Gonneville, longe de se atribuir o mérito da prioridade das relaçôes com o Brasil entre os franceses, assegurou que:

"d'enpuies aucunes années en çà, les Dieppois et les Malouinois et autres Normands et Bretons vont (ici) querir du bois à teindre rouge, cotons, guenons et perroquets".

(3). - Editado sob a direçăo de Ch. A. Julien, Les Français en Amérique pendant la première moitié du XVIe siècle, t. I (Paris, 1946).

(4) . - Entre os seus companheiros, Gonneville menciona "le sieur Coste, d'Harfleur, qui de curiosité venoit au voyage". (Ibidem, 31).

(5) . - Sôbre as relaçöes de Gonneville com os índios, cf. Ch. Verlinden, Paulmier de Gonneville $e$ os indios do Brasil em 1504 (in "Revista de História", no 39, XIX, 1959, 3-17). 
O estado atual da documentação não permite, infelizmente, encontrar uma prova formal dessa afirmação, nem quanto aos locais, nem quanto à data. Pelo menos é o que podemos depreender de uma súplica, apresentada por cinco bretões a Francisco I e transmitida a João III, notificando-lhe as contínuas viagens dos seus navios às

"terres du Brésil qui sont très grandes et dont une partie a été découverte par les Bretons et l'autre par les Portugais" (6).

Nada é mais hipotético também do que as viagens brasileiras atribuídas ao marujo de Honfleur Jean Denys em 1519 e ao marinheiro diepense Jean Parmentier, o célebre pilôto de Jean Ango, em 1520 (7). Uma coisa é certa: a documentação é, até o presente, precária sôbre a presença francesa no Brasil durante os vinte anos posteriores à viagem de Gonneville. Este tinha organizado uma tomada de contacto, visando operações futuras, sem que se possa verificar uma relação direta entre esta e aquela viagem.

O início seguro e durável das relações franco-brasileiras foi o fruto indiscutível das viagens dos irmãos Verrazani. Os principais episódios são há muito tempo conhecidos. Pode ser útil agrupar os resultados de pesquisas dispersas, mas mais interessante ainda será, entretanto, revisar e completar a cronologia das viagens, apresentar a importância dos seus resultados e suas conseqüências.

A História interessou-se pelo nome de Giovanni Verrazano, e quase exclusivamente pelo seu reconhecimento das costas da Flórida e a fundação da "Francesca" em 1523-1524; ùltimamente, muitas vêzes, cerimônias franco e ítalo-americanas o celebraram como fundador indireto de Nova Iorque. A morte de Giovanni, em 1523 na costa do Brasil durante muito tempo alimentou a história anedótica e as controvérsias dos eruditos (8). Deve-se, entretanto, não separar do nome de Giovanni o do seu irmão Girolamo e sim seguir de perto as suas intenções.

Apenas a alguns anos foi feita a mais completa justiça à ciência cartográfica de Girolamo. Porque a obra dêste último não se limita a construção de um planisfério, muito conhecido aliás, conservado no Museu do Vaticano (9). Há mais. "Cosmógrafo" ex(6). - T. T. (Tôrre do Tombo), Corpo Chronologico, I, maço 43, doc. 25; cópia em Paris, Bibl. Nat., nouv. acq. fr. 9386, f. 103, 109-110.

(7). - Ch. A. Julien, Les voyages de découverte et les premiers établissements (Paris, 1947), 21, n. 1.

(8) . - Ch. Verlinden, in "Rev. Belge Philol, et Hist.", XXVIII, 1952, 838.

(9). - R. Almagia, Planisphère de Girolamo Verrazano (in "Monumenta Cartographica Vaticana", I, 1944, no 17, pp. 53-55, pl. XXIV-XXVI) ; M. Destombes, Nautical charts attributed to Verrazano (in "Rev. of early cartographhy", 1943, 57-66). 
perimentado, Girolamo teve participação maior do que se pode crer na ciência cartográfica. Assim é que após a morte de Giovanni, êle prosseguiu sòzinho a sua tarefa.

Com efeito, houve quatro, e não duas viagens dos Verrazani. A documentação existente em Ruão e em Lisboa permite, agora, assim afirmar. Das quatro expedições, três foram a obra comum dos dois irmãos, Girolamo empreendeu sòzinho a quarta .

Giovanni desapareceu durante a terceira viagem, e não na segunda como se acreditava até agora. Não voltaremos a tratar do cruzeiro na Flórida, relatado pelo próprio Giovanni para dar ciência a Francisco I. As três outras emprêsas realizaram-se na América do Sul. Como explicar a mudança de destino, verificada apenas a dois anos após a primeira expedição?

A desaprovação, na primavera de 1524, pelos banqueiros florentinos (Rucellai, Nasi, Albizzi, Buonaccorsi, Gondi, Guadagni) de Ruão e de Lião, comanditários da viagem de seus compatriotas na Flórida tinha sido certa (10). Sem desencorajamento, entretanto, aguardavam a oportunidade de uma nova tentativa

"quelque autre coomerce profitable".

As viagens eram, por assim dizer, pesadas: desejava-se uma nova orientação e um tráfico remunerador, de maneira alguma uma exploração desinteressada. Dois anos mais tarde, mudança e proveito, eram coisas adquiridas, na América do Sul, com o pau-brasil. Mas fôra preciso esperar. E o resultado seria bem aquêle que se tinha desejado?

Apenas a nave La Dauphine tinha acabado de voltar da Flórida um outro projeto tinha sido formado: fracassou, parece, antes mesmo de ter um comêço de execução. Absorvido pela guerra continental, vencido em Pavia, prisioneiro em Madrí, Farncisco I não pôde, durante longos meses, encorajar os planos de uma hipotética expansão. Seus adversários se esforçaram em tirar-lhe todos os meios. Não foi Henrique VIII, mas João III, quem procurou subornar Giovanni Verrazano. No dia 8 de maio de 1525, em Paris, Diogo de Gouveia - que acumulava, como se sabe, a intriga diplomática com as funções de superior do Colégio de Santa Bárbara - informava a Côrte portuguêsa das suas negociações com

"um hábil navegador que voltou, no ano precedente de sua viagem de descoberta, e cuja experiência une a teoria à prática";

o que só poderia ser Giovanni. Diogo anunciava sua ida a Lisboa. Se o explorador foi ou não, nada sabemos, mas o certo é que êle permaneceu mais ou menos ao serviço dos franceses e lhes abriu, definitivamente, um acesso ao Brasil.

(10). - Sôbre o que se segue, cf. M. Mollat, Le commerce maritime..., 253-254. 
Qualquer pessoa que quisesse ver na meta brasileira dos Verrazani, em 1526, uma intenção precisa, formal e deliberada, invocaria por precedente a tradição da viagem dos Gonneville, a experiência do Atlântico Sul adquirida pelos corsários franceses (11) e, talvez, os indícios fugidios de emprêsas pouco conhecidas: uma anotação sem referência, do Hydrographie do Padre Fournier relativa a uma viagem diepense à América do Sul em 1524, a alusão de um documento do Havre de maio de 1525 a uma

$$
\text { "pequena nave que vai ao Brasil" }
$$

por conta do vice-almirante Le Roy du Chillou (12) .

No que concerne aos Verrazani, a documentação deixa entrever que êles visavam as Índias Orientais, mas que, como muitos outros, acabaram por arribar à América do Sul. Isso não é duvidoso quanto à segunda viagem. A sociedade formada em Ruão em abril de 1526 por Giovanni com Ango e muitos outros, se propunha a enviar três navios "às especiarias". Uma expressão assim tão vaga não seria uma prova suficiente; mas as cartas conservadas na Tôrre do Tombo são formais. No dia 18 de julho de 1528, d. Antônio Silveira de Meneses, governador de Sofala, recolhia doze sobreviventes da expedição; os navios tinham sido armados em Honfleur, escreve êle, para

$$
\text { "myser Joam de Varaursano" }
$$

e deviam ir às Molucas pela "Bôca do Dragão", isto é, pelo estreito de Magalhães. Na impossibilidade de transpô-lo, tinham procurado atingir Sumatra pelo Cabo da Boa Esperança, mas tinham-se dispersado e, segundo os sobreviventes, não sabiam o que tinha acontecido ao capitão e aos outros navios (13). Essses desaparecidos, por uma carta de Paris de 18 de setembro de 1527, escrita por Diogo de Gouveia, são descritos como tendo sido encontrados nas costas do Brasil

(11). - Por exemplo Jacques de Saint-Morisse ao serviço de Ango em 1523 (E. Gosselin, Documents... pour servir à l'histoire de la marine normande..., Ruão, 1876, 142); e sobretudo Jean Fleury (E. Guénin, Ango et ses pilotes, Paris, 1901).

(12). - P. Fournier, Hydrographie..., ed. 1643, p. 321, recolheu uma tradição segundo a qual dols diepenses, Guérard e Roussel, teriam descoberto o rio "maragnon". Arch. Comm. Le Havre, E. E. 87, public. por Ch. Bréard, in "Mélanges Soc. Hist. Normandie", 6.a série, p. 280.

(13) . - T. T., Col. S. Vicente, vol. I, f.o 407, publ. por Sousa Viterbo, Trabalhos Nauticos dos Portuguêses, Lisboa, 1898, I, 84. Devemos um microfilme dêsse documento à gentileza do Cdt. A. Teixelra da Mota. Sôbre êsse assunto, cf. A. Lobato, A expansão portuguêsa em Moçambique de 1498 à 1530 (Lisboa, 1954), 79-80, e M. Mollat, Passages français dans l'océan Indien au temps des frères Verrazani (in "Actes du VIe Coll. Intern. d'HIst. Maritime et du IIe Congrès Inter. de 1'Assoc. Hist. de l'Oc. Indien". Lourenço-Marques, 1962, Lisboa (in "Studia", t. 11, 1963) e Paris (in "Bibl. Ec. Htes. Et, VIe section), a aparecer em 1964. 
"Mestre João Verrazano, que era capitão de três naves com destino às índias voltou, assim como seu irmão. Isso foi devido ao fato de que os marinheiros, quando se viram envolvidos pela tempestade perto do Cabo, o obrigaram, com o seu navio e o do irmão. Quanto ao terceiro navio, dizem que passou além, sem que houvesse mais dêle noticias. Rumaram para as costas do Brasil e aí carregaram o navio de seu irmão".

Tais incidentes são comuns na história da navegação atlântica. Meta de substituição, alcançada como que a contragosto, o Brasil oferecia uma compensação de que os armadores não puderam se queixar. O episódio era decisivo.

Apenas de volta, já no outono de 1527 , os dois irmãos se preparam para tornar a partir na primavera seguinte. Os diplomatas portuguêses em França assim o atestam. Em 14 de dezembro, D. João da Silveira mandou dizer ao seu rei o que se segue:

"Mestre Giovanni Verrazano sai daqui ... o Almirante the fêz entregar cinvo naves para ir a um grande rio, na costa do Brasil, descoberta, dizer, por um castelhano ... Partirá em fevereiro ou março. Ó rio é, creio, o que foi descoberto por Christovão Jacques. Parece-me que tocarão aí e em seguida irão para maịs longe ... Êles (as pessoas) tomam por mal tudo que se quer proibir do Brasil e o Almirante falava disso não sem paixão ..." (14).

Essas informações eram exatas; mas a partida dos viajantes sofreu algum atraso. Giovanni, estava ainda em Ruão em 19 de abril de 1528, com seu associado e compatriota, residente nessa cidade, Alessandro Rucellai (Alexandre Rousselay), pois alugou um navio de Fécamp chamado Le Nicolas ou Flamengue, para ir "às Indias". Um processo relativo a êsse contrato arrastava-se, sete anos mais tarde, perante o Parlamento de Ruão. Foi durante essa viagem que Giovanni morreu. Infelizmente as peças dêsse processo fazem apenas uma alusão muito indireta, pela evocação lacônica de uma viagem interrompida brutalmente. Eis o texto na sua aridez:

"Suivant la chartre-partie, ledit de Veraceno avoit commencé faire ledit voyage, lequel par sa deffaulte au autrement n'avoit peu ledit voyage estre parfait, mays avoit chargé quelque petit nombre de brésil".

A peça acrescenta que o navio,

"contre la teneur de lad. chartre-partie, avoit esté amené avec ledit brésil au pays de Bretagne" (15).

(14). - T. T., CC. I, maço 33. doc. 57; Mollat, Quelques aspects... cltado acima, n. 2; L. de Matos, Les Portugais en France au XVIe siecle. Etudes et documents, Coimbra, 1952, 3-4.

(15). - Arch. đép. Seine-Mar., Parlement, 15 abril 1531 e 13 de agôsto de 1535. 
Após o drama, Girolamo é o único mencionado, no fim de setembro de 1529 , no afretamento de um navio de 120 toneladas, $L a$ Bonne Aventure, do Havre, destinado

"à la Terre et isle du Brésil".

Essa quarta viagem apresentava, todavia, um traço nôvo e importante: o associado de Girolamo, Pierre Bonshons, mercador de Ruão, era um freqüentador do tráfico mediterrâneo; juntos, previram a volta do navio por Ancona, Veneza, "Asye", isto é, Ayas, Cândia, Alexandria, antes de retornar ao Havre (16). Não sabemos muita coisa sôbre o resultado da operação. O rastro da atividade de Girolamo perde-se nesse setor. Ficou desencorajado pela proibição do tráfico das "Indias" comprado ao Almirante Chabot pelos portuguêses em agôsto de 1531, ou pela concorrência tornada extremamente numerosa? É difícil saber. Qualquer que seja, o motivo a cronologia retificada das viagens dos Verrazani permite atribuirIhes o mérito, voluntário ou não, de ter aberto ao comércio francês, na falta da rota das especiarias, a do pau-brasil.

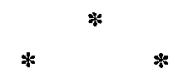

O mérito dos Verrazani parece tanto mais justificado, porque foi da Normandia que as relações franco-brasileiras se ramificaram para os outros portos franceses. O comércio francês no Brasil desenvolvia-se já em freqüência e volume na época do desaparecimento de Giovanni. Em seguida, exceção feita de alguns momentos em que as proibições de tráfico com as "Indias" portuguêsas foram suspensas, ou pelo menos mais relaxadas, o armamento de navios parece ter aumentado de ano para ano.

Em 1529, de julho a dezembro, duzentas toneladas de pau do brasil foram descarregadas no pôrto de Honfleur. Não se tratava mais de experiências, apenas acessíveis a sociedades capazes de suportar os prejuízos graças ao favor real ou às finanças italianas. Agrupados para dividir os riscos, mercadores normandos de média ou pequena importância tomaram parte desde então nos afretamentos de navios: Ruão forneceu os capitais, os portos da costa - Honfleur principalmente - os navios e as equipagens (17).

(16). - Ibidem, 'série E, Tabellionage meubles, Ruâo, 22 e 27 de setembro de 1529.

(17). - Ch. de Beaurepaire, Anciens voyages normands au Brésil (in "Bull. Soc. Hist. Normandie" 1645-1890, 236-239) . 
Em 1530, quatro navios franceses foram, de uma só vez, capturados pelos portuguêses em águas brasileiras (18). Explica-se pois a inquietação da Côrte de Evora, os relatórios alarmantes de seus embaixadores em França, o zêlo dos seus informantes, os esforços e sacrifícios despendidos, em dinheiro e em presentes, para embair e corromper o almirante Chabot: êsses esforços levaram em agôsto de 1531, à detenção de cinco navios prestes a se aparelharem de Honfleur para o Brasil (19). A proibição para os normandos interferindo "com a sua navegação", custar-lhe-iam a "sua existência" (20) . Contra essa gente resoluta, a proibição, prisão, mesmo suplícios, era pura perda de tempo.

A tese de Francisco I sôbre a liberdade dos mares longínqüos coincidia muito bem com o interêsse de seus súditos para que êstes deixassem de armar seus navios, desprezando as proibições proclamadas excessivas vêzes em 1537, 1538 e 1539, para serem eficazes. Desencadeada a pirataria, diminuiu o tráfico sem, entretanto, o suspender; os interêsses parecem ter sido levados mais em conta por êles mesmos do que pelas compensações mútuas negociadas em Bayonne a partir de 1536. Como nas outras rotas oceânicas, os normandos tomaram muitas vêzes os caminhos do Brasil. Os embaixadores portuguêses não cessaram de denunciar os seus preparativos em 1532, 1533 e 1534 (21). Neste último ano, a marinha do rei de França, ela própria, se abasteceu de pai-brasil em Honfleur. Outras partidas são atestadas em 1539 (22) .

A morte, em 1540, do almirante Chabobt, sustentáculo dos interêsses portuguêses, derrubou os últimos obstáculos do lado francês. Segundo um relatório espanhol datado do Rio da Prata, em 1541, pelo menos trinta navios franceses rumaram para a América do Sul e Estreito de Magalhães; no fim do mesmo ano, sete navios partiram de Ruão para o Brasil e voltaram no ano seguinte (23). O hábito adquirido e a enumeração das partidas anuais tornaram-se monótonas. O Brasil e os brasileiros tornaram-se familiares aos normandos e, por seu intermédio, aos franceses. Ninguém se espantou - e Montaigne de passagem por Ruão, menos que qualquer outro

(18). - T. T., CC. I, maço 44, dac. 115; La Pensée de J. Ango, tomada no mesmo ano, carregada de pau-Brasil (T. T., Gavetas, no 20 , maço 14, doc. 52).

(19) . - T. T., CC. I, maço 49, doc, 33 e Bibl. Nat. Paris, nouv. acq. fr. 9386, fos 313-316.

(20). - Segundo Gaspar Vaz, embaixador de João III em França (tothe sua vida e navegaçam), CC. I, maço 47, doc. 43 (4 de setembro de 1531).

(21). - T. T., CC. I, maço 49, doc. 61 (6 de agôsto de 1532).

(22). - Arch. Nat., J, 1961, pl. 8, no 63; Arch, dép. Seine-Mar., E, Tabell. meubles, 3 de fevereiro de 1540 ; T. T., CC. I, maço 49 , doc. 61 .

(23) . - Sevilha, Arch. Gen. de Indias, Relatórlos e descr., f. 3 (real. de Francisco Sanchez); Gosselin, op. cit., 144.

(24). - Montaigne, Essais, Ifvro I, capítulo 31 (ed. Thibaudet, Paris, 1950. 
- quando na festa brasileira executada em honra da entrada do rei Henrique II nessa cidade, no dia $1 .^{\circ}$ de outubro de 1550 (25), nela figuravam:

$$
\text { "Cinquante naturelz freschement apportés du pays"; }
$$

talvez tivessem vindo nos nove navios, de que os notários de Ruão registraram a partida em 1549: La Marguerite (200 toneladas), La Blanche (200 toneladas), Le Lévrier (100 toneladas), La Salamandre (140 toneladas), Le Cable (200 toneladas), La Victoire (80 toneladas) .

\footnotetext{
"L'une des principales choses dignes de nostre grandeur, c'est d'estre fort et grossement équippé pour la mer",
}

teria dito Henrique II assumindo a sucessão de seu pai (26). As emprêsas de maior envergadura estavam próximas; cinco anos mais tarde, em 1555, a Villegaignon deixava as costas normandas. Mas isso é um outro assunto.

Durante êsse tempo a atividade normanda tinha se expandido. Uma curiosa carta de 1534 diz que Ruão aprovisionava os armadores inglêses de animais exóticos, como:

\footnotetext{
"petits animaux venus du Brésil appelés sagouins, quùil faut nourrir de pommes, de noix, d'amandes et de lait chaud, et tenir, la nuit, à l'abri du froid, dans une boîte de nuit" (27).
}

Sem pretender que os inglêses tivessem aprendido com os normandos o caminho do Brasil, examinemos com atenção a associação formada em 1539, por dois mercadores, um de Dieppe, outro de Rye, para o envio, ao Brasil, de seus respectivos navios, sob a direção de um pilôto diepense. Ora, o que assim se fazia em Rye, praticava-se igualmente em Southampton, Portsmouth e Plymouth (28).

Com maior razão os normandos cooperaram com os outros navegantes franceses, ou encontravam nêles êmulos e concorrentes. Os bretões, bem entendido, não ficavam atrás. Ao mesmo tempo que navegavam, os Verrazani, mais ou menos em 1527, cinco mercadores bretões, Yves de "Coaqungar", François Guéret, Mathurin Tournemouche, Jean Bureau e Jean Jamet, tinham enviado ao Brasil três navios

\footnotetext{
(25) . - Arch. Comm., Ruão, Y. 28; F. Denis, Une fête brésilienne célébrée à Ruoen en 1550, Paris, 1850.

(26). - Ch. de La Roncière, Hist. Marine Française, III (Paris, 1923), 455.

(27). - Letters and papers of the reign of Henry VIII, VII, n? 1489 (Londres, 29 de novembro de 1534).

(28). - Public Record Office, High Court of Admiralty, 13, vol. 4 (27 de novembro de 1541). Informaçāo devida a gentileza de Mrs. A. A. Ruddock.
} 


\begin{abstract}
"pour y acheter et charger des pièces de bois, bêtes et oiseaux estranges";
\end{abstract}

sabe-se que as contestações oriundas da sua captura por corsários portuguêses deram margem a pretensões bretãs na descoberta de alguns pontos do litoral brasileiro (29). Os rochelenses não foram talvez os últimos; mas não contamos com arquivos sôbre êsse assunto. La Barque de Fécamp veio descarregar entre êles em 1541, mas das suas próprias viagens não temos notícias antes de 1550 (30). Em Bordéus, a documentação atualmente conhecida indica, em 1548, uma operação interessante pelo seu autor e seu destino: um mercador, pertencendo a uma família de origem espanhola muito conhecida, Diego de Bernuy, despachou pau-brasil a compatriotas seus residindo em Antuérpia. Dessa cidade, às vêzes voltava algum brasil Ruão (31) .

Os mercadores mediterrâneos já tinham entrado em cena, já a uma vintena de anos, graças, talvez, aos navegantes normandos e aos banqueiros italianos de Lyon. Em 1529, Girolamo Verrazano pretendia voltar do Brasil para o Mediterrâneo. Depois, em plena crise do "tráfico das Índias", no início de dezembro de 1531, constituiu-se em Marselha uma sociedade para o envio de um ou dois navios anualmente ao Brasil. O primeiro dêstes foi um navio de Honfleur tornado marselhês em 1529, o Pèlerine, do barão de Saint-Blancard e de Pierre du Pèret; sua captura na volta de Pernambuco, foi em agôsto de 1532 e e é muito conhecida. O valor do carregamento, 62.000 ducados, e sua composição eram sintomáticas: três mil peles de leopardos e de animais diversos, trezentos macacos e macacas, seiscentos papagaios:

$$
\text { "jam linguam nostram conatos", }
$$

algodão, e sobretudo 5.000 quintais de pau-brasil (32). O pau-brasil, antes asiático, vinha agora da América; Marselha tornou-se um mercado para o abastecimento da bacia mediterrânea: o Languedoc pela sua "draperie", Argélia, Alexandria, Beirute. Nada mais revelador, nessas condições, que o testemunho dos cônsules de Lyon, falando em 1554 dos mercadores de La Rochelle, Ruão, Dieppe e outros lugares da Normandia:

(29). - Bibl. Nat., nouv. acq. fr. 9386, fo: 92-96, 100-107.

(30). - Arch. dep. Seine-Mar., E, Tabell. meubles, 29 de agôsto de 154i; E. Trocmé e M. Delafosse, Le Commerce rochelais de la fin du XVe siecle au début au XVIIe (Paris, 1952).

(31). - Arch. dép. Gironde, $3 \mathrm{E}$, minutas notariais Donzeau (21 de janeiro de 1548); E. Coornaert, Les Français et le Commerce international à Anvers (fins au XVe-XVIe siècle), 2 vols. Paris, 1961; cf. Index: Brésil.

(32). - Texto publicado por E. Guénin, op. cit., 256-261; P. Bartas, La première tentative de colonisation française au Brésil (in "Provincia". III, 1923, 1-17); R. Collier e J. Billioud, Hist. Commerce Marseille, III (1480-1599), 1951, 286-287. 


\begin{abstract}
"qui vont chacun an aux isles du Brésil charger leurs navires de brésil, viennent la pluspart les vendre et descharger à Marseille", onde "s'en fournissent ceulx de Languedoc, Daulphiné, Lyon et tous le païs de Provence" (33).
\end{abstract}

A inversão do itinerário assim se completava: o Mar Interior prolongava os itinerários oceânicos. O que vimos Girolamo Verrazano fazer pela primeira vez, tornou-se um hábito.

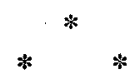

O lucro incitava os mercadores do Atlântico a voltarem pelo Mediterrâneo e isso se juntava às necessidades náuticas que os levava para as costas ocidentais da África. Os circuitos franco-brasileiros, desde sua origem, foram triangulares. As rotas normandas da primeira metade do século XVI previm habitualmente as escalas africanas: "Guynée", "terres de Guynée", "costas de Guynée", Cabo Verde, Cabo da Três Pontas, algumas vêzes o Congo (34). Da França ao Brasil, navegava-se quase em linha reta, beneficiando-se dos ventos, da proximidade relativa da África e da América, e das possibilidades de comércio. A documentação não se refere em nenhum lugar ao tráfico de escravos; um vocabulário "franco-guinnén" das proximidades de 1540 não diz nada sôbre êsse assunto e só exprime conceitos humanos e comerciais. A África fornecia eventualmente açúcar, cêra, goma, âmbar, marfim, ouro, plumas e animais exóticos, complementando os carregamentos brasileiros.

No Brasil, as regiões freqüentadas pelos mercadores franceses são, algumas vêzes, difíceis de identificar. Geralmente portos vizinhos de zonas de produção de pau-brasil. Era mais normal que os normandos sempre tivessem se interessado pela possibilidade do aprovisionamento para a sua draperie de uma substância tintorial vermelha justamente reputada. O pau-brasil, árvore de $10 \mathrm{a}$

(33). - Collier e Billioud, op, cit., 187, 499-500. E' 'provável que êsse tipo de tráfico esteja ligado ao intercâmbio regional entre o Mediterrâneo e o Noroeste europeu; qualquer navio, descarregado da totalidade ou de uma parte do seu carregamento, poderia muito bem aceitar como frete de retôrno na Normandia um carregamento de alumen, necessário, como os produtos tintoriais, à indústria textil (cf. J. Delumeau, L'alun de Rome (XVe-XIXe siècles), Paris, 1962. Um mercador como Bonshons o praticava de maneira habitual ( $M$. Mollat, Le commerce maritime..., por exemplo, pp. 416-17). Um tráfico completa e prolonga o outro: isso é cousa corrente.

(34) . - Gosselin, (op. cit., p. 142 segs.) tirou, sem esgotar o conteúdo, achegas ao assunto na muito rica informação do Tabelionato de Ruão. Sôbre as escalas africanas na rota do Brasil cf. o mas. 841 da Col. Moreau na Bibl. Nat., fo:s 25 vo, 128-131. 
15 metros de altura e de 0,80 a 1 metro de diâmetro, foi descrito nas "cosmografias" do XVI século; principalmente por Jean Alfonse e por Thevet (35). Ele é mencionado, muitas vêzes, nas cartas geográficas e localizado em locais onde cresciam mais. Vê-se, algumas vêzes, a representação das fases do trabalho, como no célebre baixo-relêvo, de madeira, de uma velha casa de Ruão: derrubada das árvores, transporte de feixes de madeira em dorso humano até a costa, transporte em chalupas, carregamento dos navios. O cartógrafo, bem informado, junta sempre comentários úteis. Assim fêz o diepense Jacques de Vau de Claye. Ao Norte do Cabo São Roque êle anota:

$$
\text { "Icy, n'y a point de brésil". }
$$

Em compensação, em face do Cabo de Santo Agostinho, e perto da figuração de uma cena de exploração, lê-se que aí é

"le chemin par où les saulvaiges vont quérir le bois de brésil, et $\mathrm{y}$ a quarante lieues de chemin depuis Sainct Domingue jusques à la forest". ridional,

Da mesma maneira vê-se, no terceiro grau de latitude mais me"La Reale, rivière: en ceste rivière se faict grant trafic de brésil" (36).

E' muito interessante confrontar mapas, manuais de navegação e relações de viagem. Anteriores ao mapa de Vau de Clayes (1579), outros mapas normandos correspondem cronològicamente à documentação que utilizamos: sem esquecer a de Guillaume Le Testu (1559), nos detemos sobretudo sôbre o mapa-múndi de Desliens (1541) e o planisfério de Desceliers (1546) (37). Um manual de navegação, datado de 1547 e em nome do habitante de Ruão, Jean Cordier, contém a enumeração e a posição em latitude dos pontos notáveis da costa brasileira do Norte ao Sul (38). A aproximação de todo êsse conjunto nos torna bem conhecida a toponímia brasileira em uso entre os marujos normandos do meado do século XVI. A toponímia do manual de Cordier, de Desliens e de Desceliers é mais rica do que a da Cosmografia de Jean Alfonse que lhe é contemporâneo (1544), mas êste contém indicações mais precisas. E' inútil recapitular as defor-

(35). - J. Alfonse, Cosmographie (ed. G. Musset, Recueil, voyages et documents pour l'histoire de la géographie, Paris, 1904); A. Trevet, Cosmographie (ed. Lussagnet, 216-217); B. J. de Souza, O pau-brasil (Col. Brasiliana no 132,1939 ).

(36). - Bibl. Nat., Cartas e planos, Ge., EE. 13871.

(37). - Ibidem, Ge., EE, 796, Cartes maritimes, constructions navales, voyages chez les Normands $(1500-1650), 2$ vols. (Paris, 1916).

(38). - Bibl. Nat., ms. fr. 24.269 , f? 20 r? e vo, 55 . 
mações fonéticas dos têrmos portuguêses. E' mais interessante lembrar alguns topônimos indiscutivelmente franceses na zona da maior produção do pau-brasil. Jean Alfonse, após ter dito que se carrega:

"force brésil"

sôbre dois rios enquadrando o pôrto de Pernambuco, entre os Cabos Arapica e Santo Agostinho, descendo mais ao Sul, rumo ao rio São Francisco e nota que:

"Entre la rivière de Para et la rivière de Perrin Maurymest la Roche de Guillaume Laye, qui est un port entre des roches, là où se charge du brésil et bon" (39).

Nossos homens compravam também pau-brasil mais ao Sul; a crônica, esta vez, completa os geógrafos. O alemão Hans Staden que tinha visto franceses carregar pau-brasil na Paraíba em 1548, conta que em 1554,

"il arriva un navire français en un port distant de huit milles de Ubatuba (talves na habia de Angra dos Reis), qui les Portugais appellent Rio de Janeiro et les Indiens Niteroi. Ici les Français ont l'habitude de faire des chargements de bois de brésil. Ils vinrent avec un canot jusqu'à notre village et achetèrent aux Indiens du poivre, des singes et des perroquets. Un d'eux descendit à terre. Il se nommait Jacques, connaissait la langue des sauvages et négocia avec eux".

O valor do testemunho de Hans Staden não é contestável; repete muitas vêzes os fatos relativos aos franceses, normandos em particular, e é inútil lembrar como êle teve a vida salva:

$$
\text { "Je suis un ami des Français". (40), }
$$

disse êle ao chefe tupinambá Ipirú-Guaçú, que o deixou partir a bordo de um navio normando (41).

A natureza amigável das relações dos mercadores franceses com os índios, principalmente os tupinambá, é conhecida. Ela resultava em grande parte, parece, de que as relações consistindo em trocas comerciais, no início sobretudo, não pareciam de maneira alguma ter ainda conhecido o regime da fôrça. Ao processo ajuntaremos apenas uma peça, muito original e pouco utilizada. O manual do ruanês Jean Cordier, citado mais acima, que contém uma espécie de guia de conversação sob êsse título:

"S'ensuyt le langaige du Brésil et du françoys".

(39). - Jean Alfonse, Cosmographie.

(40). - Hans Staden, Duas viagens ao Brasil, ed. Carvalho Franco (Rlo de Janeiro, 1942), pp. 50, 93, 128 e passim.

(41). - Bibl. Nat., ms. fr. 24.269, fos 53 ro e vo, 54. 
Oitenta e cinco vocábulos ou locuções são dispostas em duas colunas correspondentes; as expressões e as palavras indígenas estavam colocadas à esquerda e seus eqüivalentes em francês à direita . A maior parte dos têrmos traduzem relações normais, se não amigáveis, designam ou exprimem, por exemplo:

- Contactos individuais: Bonjour. Oui. Nenny. Je ne sçay ce que tu dis. Regarde, Attends. Demain.

- Conversação amigável: Comment as tu nom? Je n'ai poinct de nom. Où vas-tu? - A ma maison. Par illa. Comment te portestu? Je me porte bien. Il est bon.

- Laços de família e de amizade: mon père, mon frère, ma soeur, mon cousin, mon compagnon.

- As partes do corpo: l'oreille, le gros pouche, les dentz, la barbe, les cheveux, la cuisse...

- Alimentos, fome, sêde: eau, mil, courge. Je suis mort de faim. Je veux manger. Baille moi à manger. Donne moi à boire.

- Objetos e vestimentas: bonnet, souliers, bragues, chemyse, mouchoir, coffre, clef, patenostres, navyre, hache, serpe, cyseaulx, clou, fourche.

- Noções geográficas e climáticas: Où est ton pays? - Il est bien loing. Une estouelle. La lune. Temps. Pluye. Nuez.

Um só têrmo designa uma instituição política: Roy.

As expressões inamistosas são pouco numerosas: Je suys fâché. Je suys marry. Je ne veux pas. Va-t-en. Dois têrmos de guerra sòmente: arc, flesches.

Uma só das palavras indígenas não tem o seu equiivalente em francês e figura em numerosas colunas: imbo. Que sentido tinha êsse têrmo intraduzível em francês? Seria interessante sabê-lo (42).

Por mais limitado que possa ser o valor dessas anotações, observaremos que franceses e indígenas não se limitavam a puras $\mathrm{e}$ simples relações de troca, e que contactos de homens a homens podiam se exprimir em algumas fórmulas conhecidas de uns e de outros. As ameaças, em todo o caso, não parece ter-se dado. Isso confirmaria uma outra informação do alemão Hans Staden:

"Os franceses vem anualmente com seus navios. Trazem facas, machados, espelhos, pentes e tesouras. Eles (os índios) lhe dão em troca pau-brasil, algodão e outras mercadorias, como plumas e pimenta.. Êles são pois bons amigos" (43).

\footnotetext{
(42). - Algumas palavras tupis parecem ter formas vizinhas do vocábulo imbo, como imbe, cipó; $i m b u$, designando uma espécie de árvore, embo, broto de árvore; embiu, alimento. Farece, devido a razós paleo-geográficas (a forma do $i$ inicial) que é necessário distinguir de mibu, trombeta de guerra (eqüivalente em português: inúbia). Na nossa lista o têrmo imbo está colocado entre as palavras coxa e prego. Disso tudo nada podemos concluir, deixamos aos filólogos a solução do problema.

(43). - Hans Staden, ediçáo citada.
} 
Essse testemunho de um estrangeiro nos levará à conclusão. Sem dúvida teríamos muito a dizer ainda sôbre as modalidades da armação de navios em França com destino ao Brasil na primeira metade do século XVI: armação de navios por empreitada, subdivisão das cotas em quatro e em oito, divisão dos gastos e dos lucros entre os abastecedores em consequiência do prorata do carregamento trazido, adiantamento ao capitão de uma parte do frete em moedas de ouro e regulamentação do sôldo após a volta, escôlha e pagamento do pilôto pelos que alugavam os barcos e o vatrão do navio com uma parte $(1 / 6)$ dos lucros líquidos, empréstimos, cauções, penhores. As formas jurídicas eram as da armação de navios destinados a mares longínqüos em geral (44).

O conhecimento mútuo dos homens com suas conseqüências diversas foi. ao lado das trocas comerciais. um resultado dos contactos tomados durante a primeira metade do XVI século. O fracasso dos proietos de uma "França Antártica" no XVI século, como no tembo de Luís XIII, suspendeu, sem dúvida. a implantacão de uma influência francesa profunda e durável no Brasil. Mas em França o Brasil era conhecido mesmo pelas mais humildes pessoas das regióes costeiras. Proporcionava aventuras heróicas e lucros para os que voltavam, lágrimas para as famílias angustiadas pela volta do marujo, o Brasil, ao mesmo tempo suscitava a atração do maravilhoso, a angústia e as lágrimas. A inquietação das famílias à espera do marujo que partira para o Brasil, aparece vivamente num poema do navegador diepense Jean Doublet:

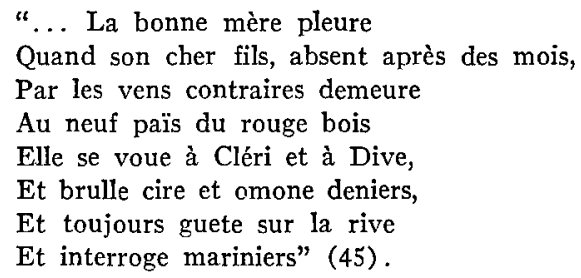

A coisa não valia a pena, e, aliás, quantos ganharam sem jamais terem partido. O Brasil tornou-se o símbolo do lucro. Com o lucro, o exotismo encontrou aí sua saída. Eram os brasileiros modelos dos "selvagens" da célebre frisa de Saint-Jacques de Dieppe? e os figurantes do "mimo" oferecido pela cidade de Ango a Francisco I em 1527? Ao lado dos 50 índios autênticos da festa dada em honra de Henrique II em 1550, 250 normandos concordaram em disfarçar-se, para apresentar ao rei uma visão real do Brasil; a gravura é tão ex-

(44). - M. Mollat, Le commerce maritime..., 406-423.

(45) - - P. Blanchemain, Les Elégies de Jean Doublet (Ruão, 1869), n̊ XI. 
pressiva quanto a descrição. Quanto às imagens do Recueil de la diversité des habibts (1562) elas popularizaram em França um tipo humano para o qual se orientavam suas simpatias. Quando se lembra a conversa de Montaigne em Ruão com um chefe índio do Brasil em 1562 , e as festas "brasileiras" dadas, nesse momento, em outras cidades francesas.

Em definitivo, apesar dos fracassos, ninguém perdeu seu tempo. As emprêsas da primeira metade do século pareceram inicialmente sem futuro, comprometidas que foram pelas ambições políticas e derrotas militares da geração seguinte. De fato, foi bem entre 1527 (ou 1504) e 1550 que as relações franco-brasileiras foram iniciadas, para o futuro, como um laço durável e fecundo de intercâmbio pacífico e de amizades humanas. 